\title{
EFFECTS OF CLIMATE CONDITIONS IN FORMATION AND DEVELOPMENT OF ZONUZ'S HISTORICAL GARDEN CITY ARCHITECTURE
}

\author{
Hassan KHALILI ZONOUZ \\ Department of Architectural Theories and Conservation, Faculty of Architecture, \\ Azerbaijan National Academy of Sciences AZ1073, 115, H. Javid ave., Baku city, Azerbaijan \\ E-mail: hassan.khalili@parasmoon.com
}

Received 10 February 2015; accepted 04 May 2015

\begin{abstract}
Zonuz architecture has originated from prehistoric era by having worthwhile architectural signs of the Kura - Aras culture related to Bronze Age (3800 BC), as seen in Qiz Qala and Oğlan Qalasi, located about $5 \mathrm{~km}$ from the city. This architecture by the dry stone method is standing at the top of the mountain and has been made of field stone which was undoubtedly outstanding in its period. This technique has reached its style as back to back diagonal stones placed within $30-45$ different degrees among them with respect to the wall making evolution during the period of 6000 years. This method has been used in all buildings and walls of house-gardens of the city for millenniums appropriately. The technique reveals that instead of brick, natural elements with more resistance have been applied. Availability of travertine is the reason of using it along with mortar in order to constructing the entire city and many other buildings. However, in some cases like Qizil-Korpi bridge plaster has been used and in some others - that needed more strength - a composition of lime and clay is applied. But it can be acknowledged that the structure of the building and foundations is part of the natural environment. Urban areas in this location have developed condition of constructing new architecture and house-garden urban engineering in terms of more convenient natural situation including better utilizing sun light, more appropriate slope as well as plenty of springs - about 360 . This is a city with spatial shape which is integrated with natural beauty of Azerbaijan and has created a rare house-garden quality. Although urban engineering and architecture of this city have got an outstanding index and many articles have been published in the field of Geology, Geography, Philosophy and so on, but nothing can be found about its architectural report, techniques and thoughts throughout the resources. The aim of present research is based on finding out topography and climate conditions effecting the architecture and city planning; in this article the author also tries to mention Zonuz architecture and type of architectural spaces and its structures in order to make a better understanding and increasing sensitivity about the building and urban setting, conservation and restoration. In order to come to a conclusion we had to choose a method for this subject and going through library shelves seemed to be real poor; hence we had to do site study and consider actual cultural, technical and historical cases and their relation with topography and city planning.
\end{abstract}

Keywords: Zonuz, architecture, architectural theories, heritage conservation, urban structure.

\section{Introduction}

The human's living environment includes all kinds of places for his exploitation purposes such as dwelling areas, food warehouses and cattle housing, which form his main existential connection with his everyday life. Obviously these areas are influenced by one's daily relationships and the identification of dwelling buildings in all historical cities has been created through them (Falamaki 2008). There are other connecting sections such as services, welfare systems, educational and religious associations available for residences which also influence on urban design culture indirectly. These are the exact spaces that form urban architecture as long as dwelling architecture and define the Zonuz's identification is considered.

The historical and touristy city of Zonuz's dwelling spaces as the major livelihood spaces in a whole traditional and modern framework are exposed to plenty of changes from past up to now. Zonuz's special climate and nature as well as its actual/potential capabilities have played great roles in forming dwelling architectures and occasionally complex structures which meanwhile are the reason for establishing various 
exclusive perspectives of special neighborhood units in its mountainous temperate nature and particular gardens and rock sites.

\section{Structure of forming}

Natural factors specially topography and plenty number of springs have had a great impact on shaping the texture and routes in the way of city's growth towards the Northern part as shaping routes in topographic lines overcoming high differences of altitude and creation of springs and water routes also play important roles in shaping its neighborhoods and routes (Parasmoon 2008).

Appropriate weather and climate, high quality and productive soil for horticulture and also the great number of springs in the city provides for the residents to build their houses as kitchen garden. It is different from those cities and villages with an economical base on horticulture. This, can be observed in the nearest urban or rural populations with their separated houses from gardens. The organized residential units as kitchen garden combined with the present topography creates a special view for Zonuz city as a unique type (Fig. 1).

The city is formed as aligned mainly because of the present topography. The slope of suburban area is mainly toward west and southwest direction. Its central part from Beheshati and Takhti Sport Complex to Northern part of Imam Khomeini St. has a slope of 5\%. From this part toward Zonuz Chai Riverin Southern area and from North of the city toward the valley, the slope increases. The general urban slope is higher than the central town in Khaje Khan neighbourhood. Initially, Marand city was connected to Zonuz city via Hafte Cheshme Lane and Sidlar Lane but at the moment, this connection is available via Ramana with a high slope. These changes in the gateways have made more diversity in urban texture and its development during the past years. Additionally, the old gateways like Harzandat also Mahal Qara Dagh is presently ruined because of a replacement for routes from Djolfa, Marand, and Ahar cities.

The availability of main highways is from west and east. The central core and historical texture of the city was Bazar and Jama Masjid (main Mosque of the city). The main route so called as shop line provided a connection for quadratic neighborhoods and urban exits toward Marand, Jolfa, Gharadagh and Harzandat.

\section{Structure of urban neighborhoods}

A neighborhood provides opportunities for informal greetings and social integrity. The residential neighborhoods with discrete boundaries and also closed ones are elements of traditional structure of development. The neighborhoods developed based on racial, religious, legal characteristics and sometimes social situation. Sometimes, the integrity of neighborhood was based on their religious or lingual identity (Parasmoon 2008).

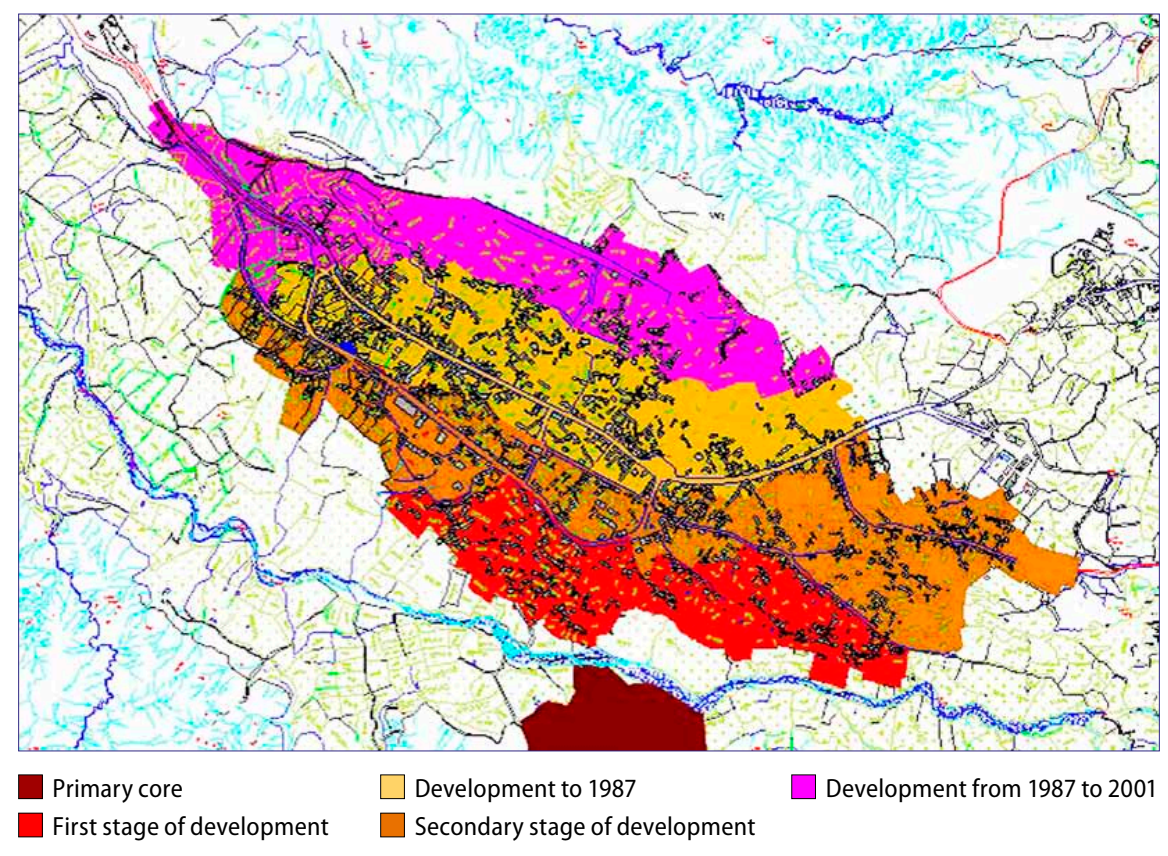

Fig. 1. The staged development of Zonuz city (created by author) 
The center of a neighborhood is considered as social focal point and a public area for social gathering. These centers were organized generally as small squares with regular or irregular geometric shapes with small bazaar, mosque, cemetery, water storage and other religious places, schools and service areas located around them. The center of neighborhood is aligned as a part of main route of neighborhood (Falamaki 2008). The holy cemetery is a main factor for shaping a center in a special place. Diversity makes urban identity rich. A good neighborhood should provide a balance among residents' willingness for their privacy, greetings, help seeking, and partnership (Saleh 1992). An important principle in urban planning is the scenic vista of meeting and gathering forums (Ahunbay 1996). The present urban plan of Zonuz city consists of four main neighborhoods named Dibin, Sidlar, Khan Khaje, and Mirjan with discrete residential texture and organization of special placement (Fig. 2).

The dominant dwelling pattern of this area is originated from close and inseparable relationships between major livelihood activities among the residences and its convergence obligation. The building constructors are motivated for considering their living areas like small sample of charming pleasant orchards of apple and apricot productive gardens, sown field, the interest of dairy needs and nature composed with life quality so as to be able to strengthen their own gardening cultures more as well as presenting them to viewers (Fig. 3).

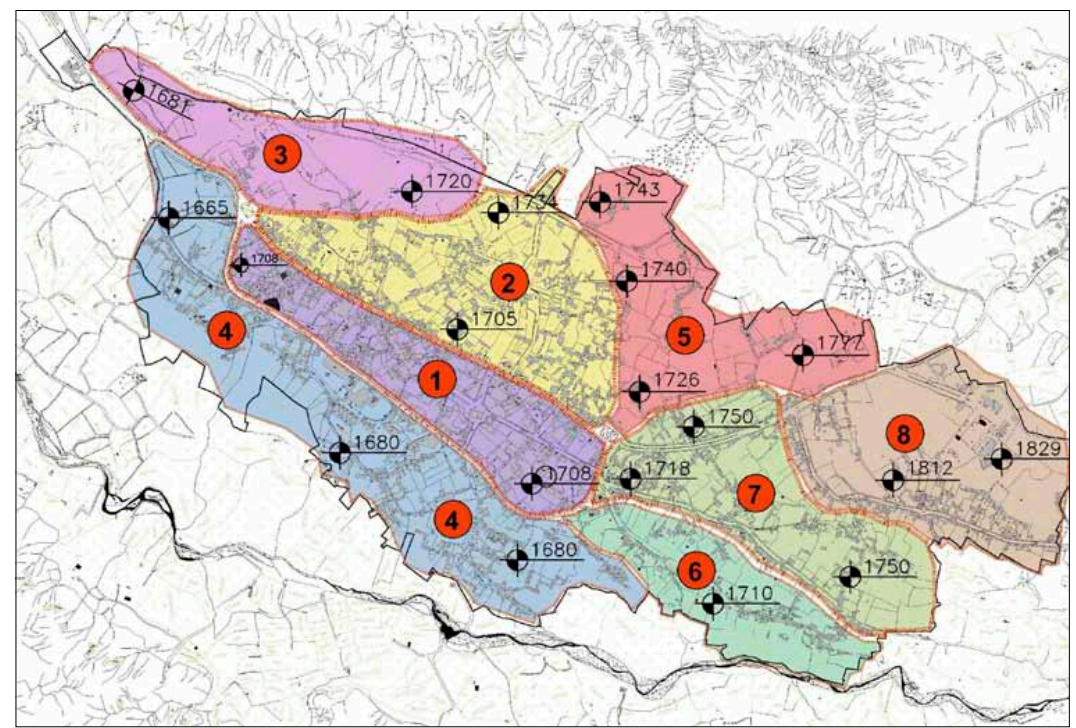

Fig. 2. The blocked city (created by author)



Fig. 3. A panorama view of garden city (photo by the author) 
The whole framework of dwelling architecture in this area has been converted to house-gardens according to these populations' special life style, their convenient situation versus gardeners and cultivators in other cities and also their willingness for creating beautiful, comfortable buildings based on current architectural principals. In accordance with all mentioned above, Zonuz's dwelling spaces can be divided to three separated parts:

Part 1: Single-familial residential units - open houses; Part 2: Garden villa houses - houses;

Part 3: Multi-family residential apartments -multi-dwelling units.

\section{Quality and space verity in urban feature}

From past till today (Fig. 4), the buildings with simple forms in one or two floors (a floor on the ground) with a general plan influenced by northern frontier and having south passages are considerable part of the Zonuz's dwelling structure and make uncomplicated spaces (Part 1).

The plan of these units shows that residences living here lack wide space for cattle housing or productive warehouses; it demonstrates that they do not own huge houses and gardens maybe because they were working in other's lands and gardens for small wages or perhaps they belong to industries or service categories.

Surrounding walls of these buildings are mostly located in one side and they all contain the total package of buildings just by making small open spaces measured between $200-500 \mathrm{~m}^{2}$ for summer crop cultivation and orchards.

Buildings with different shapes and sizes by similar planning along with different details among orchards placed far from those surrounded walls are suitable places for living and those dispersal segregated textures create neighborhood units (Part 2). These spaces illus-

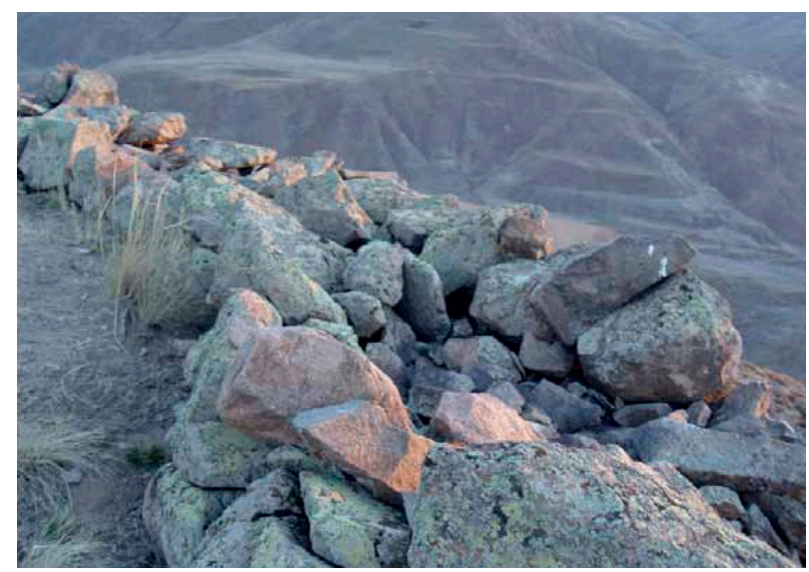

Fig. 4. A part of Qiz Qala wall 3800 B.C. (photo by the author) trate the set of Zonuz's attractive house-garden vista throughout its mountainous climate and staircase-like gardens among different samples influenced by different factors altogether. The outdoor environment, extra multiple yards, and tetrahedral pavilions have all neglected the hardness of pertaining the architecture of cold regions and sometimes huge-sized gardens are decorated by rock\& brick statues in the middle. But the very noticeable turning point of Zonuz' architecture is exclusivity and particular dissimilarity of garden-villa architecture among its houses. The comperehensive spaces -sometimes symetrical geometric shapes- are categorised by different approaches with respect to space designing principals and definiatly influenced the lives of their residence. The particular spatial compositions driven from general architectural rules such as protractions and developments, aristocracy, hierarchy and circulation, regularity and symmetry, repeating and rhythm, homogeneity and contrariety are the contexts which are visible in this town. Simple and universal volumes are described generally and appealing in terms of alignments, availability and other contexts which won't make their viewers confused but will be understood by them easily. Of course, influences of units in Part 2 on urban spaces and their availability as noticeably separated walls have made them beautiful in a simple manner and easy to understand.

Along with these original and historically designated parts, there are some houses which are unpleasantly and forcefully constructed in this urban feature in recent years due to mismanagement and unplanned urban massive decisions that is extremely against culture, and architecture of Part 1, 2 buildings. These new buildings are just like accumulative structures and apartments same as populous cities and still under construction (Part 3). They are made from metal and concrete, appearing from between the ancient pleasant gardens and affecting their beauties. They will absolutely cause some risks as well as disturbing residential welfare and spatial security of house-gardens in Part 1, 2 - those scarce units as traditional patterns - if the authorities do not oblige them to have proper planning.

\section{The formation and development of buildings}

Establishment plan of all groups of buildings has been affected by their placement in different areas and it was also subject to factors such as restriction of each of the four quarters, adjacency to different gradation of passageways, and positioning in the sloping or relatively flat areas. But in general, this positioning is assumed to have an east-west direction of extension due to the demand for greater utilization of adjacent passageways 
which lead to one of the main walls of the building volume (Municipal Zonuz). Following the vast geographical conditions of Zonūz and its topography, it has an east-west direction of extension. Longitudinal stretching along the axis of the valley, urban development and east-west extension of buildings are factors that help to take the utmost advantage of the lightest absorbent side and towards the beautiful south side of the Zonuz valley and thus urban landscape formation of mentioned units. This plan extension, in terms of capacity constraints in height and depth in order to take advantage of the best light and most perspective, required those areas to be placed and developed linearly parallel to one another on a horizontal line (sometimes with a trivial fracture). Moreover, height and width of buildings could not be extended, hence developing new spaces took place within the area of the yard (buildings in group one).

In the meantime, there has been greater freedom in locating the buildings in group two due to their housegarden identity and the possibility of establishing the building in any area. Some units did not follow the general pattern, i.e. towards the south in a way that positioning in the most northern point of the land has changed in the southern area of the building to use the yard; and its unique sample is the house attributed to Hassan Fani. In this house, the main courtyard is located on the north side and the interesting point is that there are no openings towards the south and all the light is provided from other directions.

\section{The effect of light on the arrangement of spaces}

Buildings arrangement in the east-west direction, as the most influential factor in the designingof linear, parallel, and light-absorbent areas caused the main building spaces to have a favorable light and only few areas are designed and built without access to the southern warm light. This provides an advantage over the main areas to be located in the light direction and spaces benefit from the light in one direction.

\section{Interior divisions of the building (floors, diversity of spaces, main and subsidiary spaces)}

The units in group one were usually designed and built in one or two floors. The main axis of the building was the location for different areas depending on the complexity of its inhabitants' relationships, including 1 . the entrance hall or vestibule; 2 . wood shed and barn; 3 . fruits and crops storage; 4 . staircase that mainly led to the other side and the courtyard; 5. living rooms and guest rooms next to each other with parallel doors; and finally the kitchen and livestock housing which was located alongside the main volume and often separately on the other side of the courtyard. Restrooms were located alongside the main volume and on the ground floor in recent cases and they were located on the other side of the courtyard in traditional cases. In one-floor units, the barn, storehouse, and entrance vestibule were unified, and all the rooms and spaces were located next to each other. In such buildings, the main corridor was located alongside the depth of the building, separating clean and dirty spaces from each other. In this type of units (two-floors), rooms, living rooms and guest rooms are located at $100 \%$ volumetric efficiency on the upper floor (for structural stability) after passing through a small corridor, usually built as two small rooms and a larger one (alongside the doors of the same height in the opposite direction).

Buildings in group two are the ones in three spatial levels (Fig. 5) separated in terms of necessit including places for keeping livestock, fruits storehouse and hayloft, and entrance vestibule on the lowest floor. These spaces have either been constructed as ground floors or designed as the basement. These floors have been built by thick piers (up to $80 \mathrm{~cm}$ ) and unique arcuate roof coverings at the height of about 2 to 2.20 .

The next level includes the main floor of the building with spaces like those of the buildings in group one, but with better quality and greater variety. Rooms were constructed based on the hierarchy of workers - guest living and Shah-Neshin (alcove), completely decorated all around based on the spatial value, and niche and ledge decorations based on linear design principles in one direction, and identical parallel doors; there were differences in rooms areas for the purpose of prioritization of the original alcove space at the approximate height of two floor (Figs 6, 7).

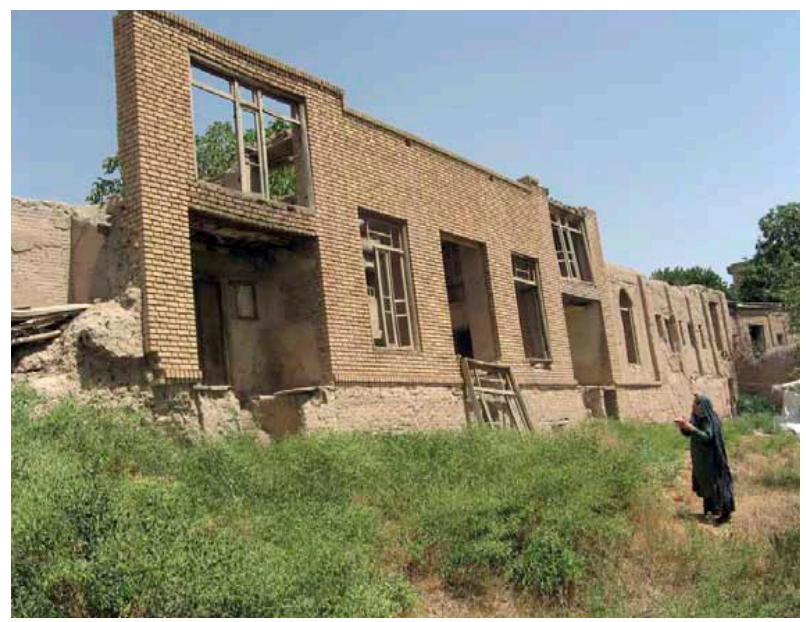

Fig. 5. Hashemi house: a sample of buildings in group two (photo by the author) 




Fig. 6. Plan of first floor of buildings type two (created by author)

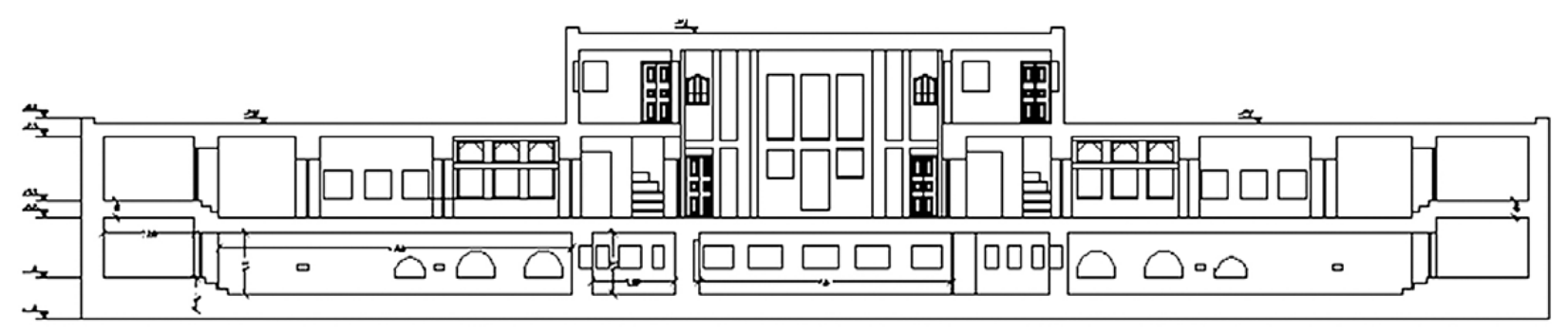

Fig. 7. Evolution north (created by author)

The third level usually consisted of an upper chamber with accessibility via staircase with a $90^{\circ}$ turn with seven to eight steps approximately. This area was connected to the alcove space through the internal windows. It is assumed that women would make a gathering in special events such as festivals and stage plays and they were in connection with Shah-Neshin place through these windows. These spaces were located clearly and precisely next to each other in the very beautiful and the unique example of the complete design of this type of units is a house attributed to Haj Taqi. Functional beauty, the variety of the skyline and symmetrical facade of this building indicate its architectural design.

\section{Techniques, implementation procedures and materials (including foundation materials, walls, facades and coatings)}

Buildings in group one and two are orderly, mostly symmetrical and proportional, with linear combinations and approximate proportions of 1 to 3 (width to length), in a 3 to 4.5 meters span - effected by the length of the wood coatings - which have structural stability by the technology of transferring the structure load through the piers to the foundation. Technology of structural lateral support occurs through struts and lateral underpinning which are $70 \mathrm{~cm}$ thick in the floor height and $50 \mathrm{~cm}$ wide at a height of 4 meters. Wooden pieces in various thicknesses (stronger in the upper level) are placed around the pop-ups to play the role of lintel in addition to create the frame. The depth of plan setback or protrusion was no more than 5.1 depth of the building in all of them as if the builders considered the overall discipline and relative symmetry of the building in order to have greater resistance against lateral forces, especially the force of the earthquake (Feilden, Jokilehto 1993). Meanwhile, in regard to the selection of the suitable position of the staircase and entrance vestibule in the center of the building with thick perimeter piers, it was attempted to create the appropriate gravity point for optimal transfer of major lateral load and to balance the load of external piers. The techniques and construction procedures of these buildings mainly follow a general pattern considering traditional techniques they use; as the stone foundation is formed by limestone rubble and clay mortar in which volume and height of the building havebeen the main factors of the variation in thickness and height of the foundation. Also regarding the piers, if the building was constructed in one floor, thatch materials were used in external walls, plaster and soil in interior walls (separators), and dry rubble stone in walls surrounding the place and the yard (Fig. 8a, b).

\section{Roof and floor coating}

Roof coatings are mostly traditional, made of wood coating suitable for flat surfaces. To do that, just like other parts of Azerbaijan, wooden beams made of poplar tree have been used. Wooden beams in the average distance of $60 \mathrm{~cm}$ (center to center) and an average diameter of $15 \mathrm{~cm}$ and wood tamping form wooden splints of $1 \mathrm{~cm}$ thickness were applied and 
a)

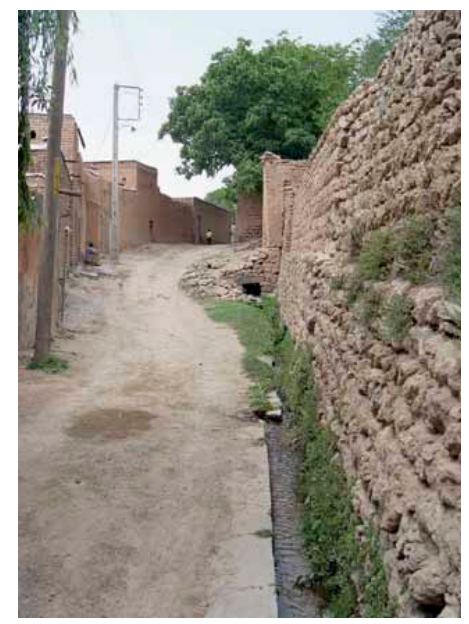

b)

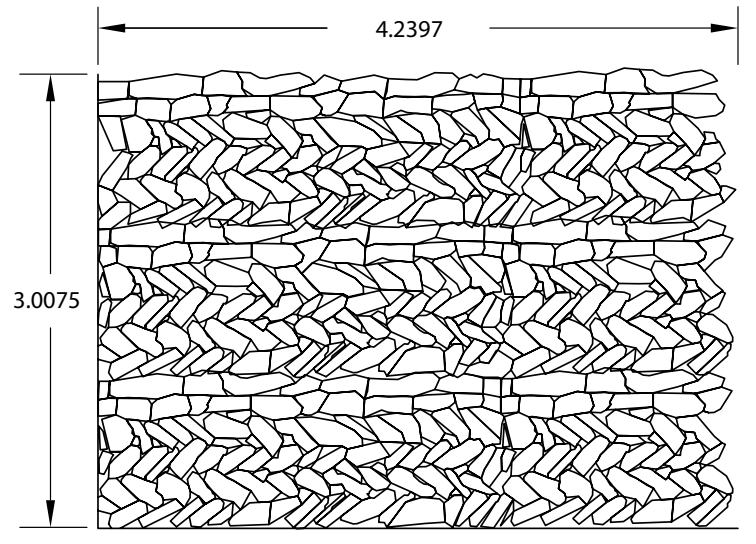

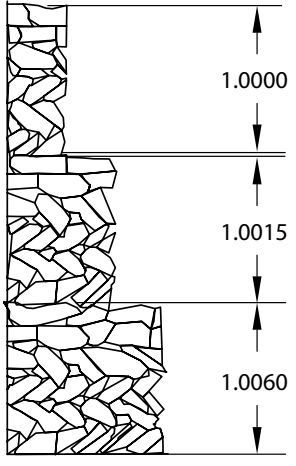

Fig. 8. Technique of picking walls by stone in Zonuz (created by the author)

Senecio herreanus was poured on it for 15 to $20 \mathrm{~cm}$ thickness and finally it was covered by $10 \mathrm{~cm}$ thatch.

In rare cases of buildings with basement, and storage space or stable, ceiling track (ridge) technique was common. Ridge ceilings were applied using limestone rubble and clay mortar and sometimes soil and plaster mortar.

Handmade clay bricks of $25 \times 25 \mathrm{~cm}$ thickness, dark plaster and soil mortars were mainly used in floor coatings and stone was rarely used in flooring.

\section{Windows}

Decorated wooden arched windows which were often in small sizes and mainly used for lighting the ground floor and storage space (according to previous statements about the division of spaces), were made of dry stone components (slit and tongue or fasten- ing), and functioned as decorative components of the building beside their main purpose of providing light (Fig. 9).

Large and wide wooden windows were designed and built in large sizes with 2 divisions in geometric shapes such as square and rectangle. These elements play an important role in the perspective of main rooms and their size does not correspond to that of the windows of houses in cold regions (Rapoport 1979). It is observed that the heat-absorbent value of the light did not have much influence on the largeness of the pop-ups and cooling technology could have not limited these sizes.

\section{Decorations}

From among the decorations used in these buildings one can notice ledges on the walls or under the windows for putting decorative objects or objects of
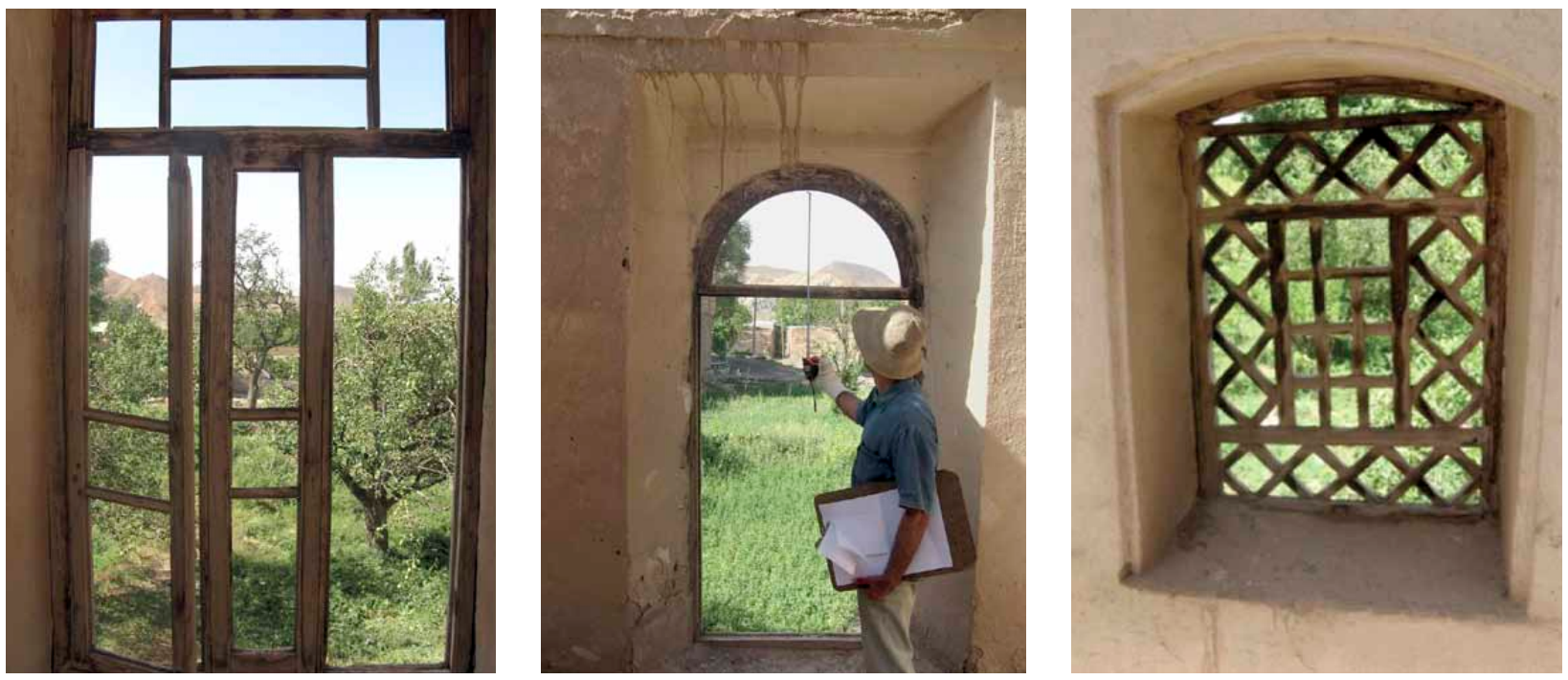

Fig. 9. Some of windows types used in buildings group $1 \& 2$ (photo by the author) 
lesser usage. The ledge line rotated around the room and had a great decorative role in the building. In alcove (Shah-Neshin) houses of the rich and type two house-gardens, using cornice on the ledge was among the artistic elements of the building. Armoire is the same as closet that is used in new buildings. In some buildings, candlesticks (lightning placement), and fireplace in the walls and fire pan (hearth) in the flooring are also observed.

\section{Access and communication spaces}

Communication spaces, including alleys and passageways between neighborhoods and gardens with various spatial diversities and interesting and beautiful scenery are among the most superior structural characteristics of Zonuz identity (Fig. 10).

What enhances the beauty of these places is that these roads are located on the slopes and they pass through the gardens and the house-gardens. Various combinations of texture rough and smooth, such as color, light, and even the odor are among the main entities of this city.

\section{Conclusions}

The architecture of this city is an indicator of old habitation and the numerous architectural monuments proves its distinction from other populated areas.

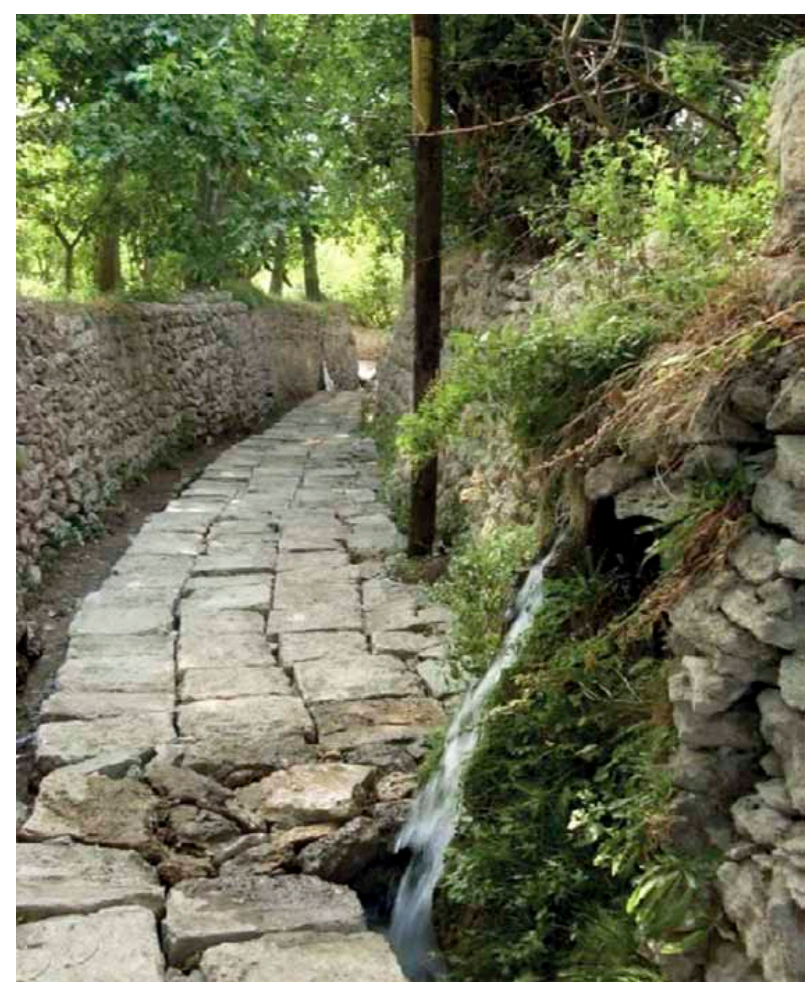

Fig. 10. A historical alley in north part of city (photo by the author)
Walling and dry stone styles benefit from a unique technique that has not been seen anywhere else. But in terms of the spatial form of the buildings and roof coatings and pop-ups, there are evidences of consistency with the architecture of the cities on two sides of Arax River. The architecture that has been developed through the history, and besides meeting the basic needs of residents, it has progressed adaptation with the climate (Johnson 1994). Thus it is considered as a good sample of sustainable architecture over six thousand years of its lifespan. In addition, its urban growth has also been achieved linearly by the proper measurements and planning based on market and four quarter centers.

Urbanism in sloping sites, which sometimes include slopes of about 30 degrees, is a sign of cognition and urban design in accordance with its metropolitan area, and layout and the surface of the structures among garden spaces creating house-gardens with stairs, has created an exclusive spatial framework in a way that it is greatly distinctive from its nearest populated places.

\section{References}

Ahunbay, Z. 1996. Tarihi cevre koruma ve restorasyon (Turkish Edition). Istanbul.

Falamaki, M. M. 2008. Revitalisation of historical monuments \& cities. University of Tehran.

Feilden, B. M.; Jokilehto, J. 1993. Management guidelines for world cultural heritage sites. Rome: ICCROM.

Johnson, P.-A. 1994. Theory of architecture: Concepts, themes \& practices. New York: Van Nostrand Reinhold.

Municipal Zonuz [online], [cited 8 February 2014]. Available from Internet: http://www.zounozcity.ir/homepage.aspx? site $=$ DouranPortal $\&$ tabid $=1$ \&lang $=$ fa $-I R$

Parasmoon co. Ltd. 2008. City development project of Zonuz for turism purposes. Tehran.

Rapoport, A. 1979. On the cultural origins of architecture. Mc Graw-Hill.

Saleh, A. S.; Helmi, F. M.; Kamal, M. M.; El Banna, A. F. E. 1992. Study and consolidation of sandstone: Temple of Karnak, Luxor, Egypt, Studies in Conservation 37(2): 93-104.

\section{HASAN KHALILI ZONOUZ}

Department of Architectural Theories and Conservation, Faculty of Architecture, Azerbaijan national academy of sciences AZ1073, 115, H. Javid ave., Baku city, Azerbaijan

E-mail: hassan.khalili@parasmoon.com

Lecturer at University of Applied Science and Technology, Managing Director of Parasmoon Company. PhD candidate at Architectural Theories \& Conservation in Azerbaijan National Academy of Sciences. He has written extensively in professional journals, e.g. Journal of Conservation and Restorations. Research interests: architectural and urban conservation, historical textures and buildings, city development, museum planning. 